\title{
Contando a história da Geografia do Colégio de Aplicação da UFRGS: uma entrevista com o professor Fructuoso Rivera Paladino
}

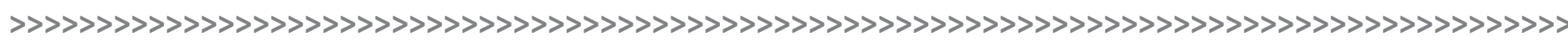

Victor Hugo Nedel Oliveira*

Fructuoso Rivera Paladino**

\begin{abstract}
Resumo:
O professor Fructuoso Rivera Paladino foi professor de Geografia no Colégio de Aplicação da UFRGS entre os anos de 1982 e 2004 . Vivenciou diferentes momentos históricos em seu espaço e tempo de trabalho. Este artigo apresenta uma retomada de sua carreira, dando destaque para suas experiências de vida, acadêmicas e profissionais, bem como assinalando práticas de ensino de Geografia as quais o professor Rivera reconhece como de destaque. São apresentadas sínteses analíticas da vida e obra deste professor que colaborou na construção de um ensino de Geografia diferenciado. Para finalizar, o professor Rivera apresenta, a partir de suas experiências, algumas pistas para os jovens professores de Geografia.
\end{abstract}

\section{Palavras-chave:}

Escola. Geografia. Educação.

\section{Resumen:}

El profesor Fructuoso Rivera fue profesor de Geografía en el Colegio de Aplicación de la UFRGS entre los años 1982 y 2004 . Vivenció diferentes momentos históricos en su espacio y tiempo de trabajo. Este artículo presenta una retomada de su carrera, dando destaque a sus experiencias de vida, académicas y profesionales, así como señalando prácticas de enseñanza de Geografía a las que el profesor Rivera reconoce como de destaque. Se presentan síntesis analíticas de la vida y obra de este profesor que colaboró en la construcción de una enseñanza de Geografía diferenciada. Para finalizar, el profesor Rivera presenta, a partir de sus experiencias, algunas pistas para los jóvenes profesores de Geografía.

\section{Palabras clave:}

Escuela. Geografia. Educación.

\section{Introdução}

O ser professor e o regate da vida dos professores vêm se intensificando na produção acadêmica recentemente, tornando-se uma importante temática da análise contemporânea sobre os profissionais da educação. As inquietações acadêmicas e profissionais com a formação de professores e com a profissão docente ganham sentido também a partir de tais regates e de suas consequentes análises.

Buscando colaborar no encontro de respostas para as questões educacionais da contemporaneidade, pesquisadores do campo da educação vêm investindo em estudos

\footnotetext{
* > Mestre em Geografia pela Universidade Federal do Rio Grande do Sul- UFRGS. Doutorando em Educação na Pontifícia Universidade Católica - PUCRS. Professor de Geografia do Colégio de Aplicação da UFRGS. E-mail: victornedelcap@gmail.com

** > Professor de Geografia aposentado do Colégio de Aplicação da UFRGS. E-mail: frpaladino@gmail.com
} 
voltados para memórias e trajetórias docentes. Autores como Castro et al. (2005), Fontana (2000), Freitas (2000) e Vidigal (1996) já desenvolveram estudos a respeito do resgate da memória de professores e encontraram importantes achados de pesquisa que colaboraram na reflexão de suas práticas docentes no contemporâneo.

Uma forma importante de resgatar o passado é ouvir antigas professoras e antigos professores que exerceram a docência em outros tempos, tempos estes nos quais os problemas na educação eram outros e as realidades social, econômica e política do país eram diferentes.

Desta forma, buscando contribuir com as presentes discussões em torno da profissão docente e da formação de professores na escola básica, ingressamos no túnel do tempo para resgatar, junto aos professores de Geografia aposentados do Colégio de Aplicação da UFRGS, aspectos da sua profissionalidade docente que acabam construindo distintas práticas de ensino de Geografia, as quais merecem memória, destaque e aprendizado.

Este artigo configura-se como uma experiência piloto do Projeto de Pesquisa "Memória geográfica do Colégio de Aplicação da UFRGS: resgate das narrativas de professores de Geografia do CAp/UFRGS”, que busca justamente resgatar as memórias do ensino de Geografia no Colégio de Aplicação da UFRGS, a partir das narrativas de professores de Geografia da instituição já aposentados.

O professor Fructuoso Rivera Paladino foi professor de Geografia no Colégio de Aplicação da UFRGS entre os anos de 1982 e 2004. Vivenciou diferentes momentos históricos em seu espaço e tempo de trabalho. Este artigo apresenta uma retomada de sua carreira, dando destaque para suas experiências de vida, acadêmicas e profissionais, bem como assinalando práticas de ensino de Geografia as quais o professor Rivera reconhece como de destaque. São apresentadas sínteses analíticas da vida e obra deste professor que colaborou na construção de um ensino de Geografia diferenciado. Para finalizar, o professor Rivera apresenta, a partir de suas experiências, algumas pistas para os jovens professores de Geografia.

Entrevistador: Conte-nos um pouco sobre sua trajetória de vida pessoal, acadêmica e profissional, antes de chegar ao Colégio de Aplicação da UFRGS.

Entrevistado: Sempre fui um apaixonado pela geografia, história e literatura. A geografia sempre me interessou muito. Assim, na década de 1960, mais precisamente em 1965, me inscrevi para concursar no Instituto de Professores Artigas, centro de ensino que prepara professores para o Ensino Secundário (Ensino Médio) em todo o Uruguai. Este centro de estudos de formação docente era de grande prestigio e competência tanto a nível nacional como internacional. Simultaneamente estudava na faculdade de Ciências de Montevidéu Geografias Física e Humana, com excelentes professores de renome nacional e internacional. Os cursos incluíam trabalhos teóricos e práticos, trabalhos de campo e seminários a nível nacional e internacional. Mas, a partir de 1971, começou o processo ditatorial comandado pelos militares, e em 1975, a situação estava muito complicada e comprometida para os professores em todos os níveis, mas fundamentalmente em relação às Ciências Humanas. A situação estava insustentável para os professores em todos os níveis do ensino teórico prático. Assim, em 1978, conheci em Montevidéu um técnico de microfilmagem que ensinava essa nova tecnologia de comunicação. Através dele consegui um contrato para ir a Porto Alegre para trabalhar. Em 1981 fiquei sabendo que na UFRGS eu podia conseguir uma vaga mediante concurso. Fiz minha inscrição como professor de geografia em julho de 1982 para o Colégio de Aplicação na área de geografia. Tratei de praticar o idioma português tanto na parte falada como na escrita. Tinha várias pessoas para uma vaga. Acho que meu 
curriculum vitae ajudou bastante. Bom, então comecei a lecionar no CAp de 2 de agosto de 1982 até dezembro de 2004. No início foi bastante difícil, mas como o colégio de Aplicação naquele período tinha uma clientela muito boa, e a maioria dos alunos que estavam cursando o Colégio de Aplicação provinham de uma determinada elite de Porto Alegre, que já conheciam não só o Uruguai e a Argentina como quem vai ao cinema, mas eles viajam para Europa, que naquela época não era tão frequente como agora. Então, o português não foi um obstáculo, como eu já falava francês e tinha conhecimentos de italiano pelo curso de direito, a escrita do português não era um problema porque tínhamos a mesma raiz. O problema era a comunicação. Os alunos foram muito queridos, inclusive em muitos fins de semana faziam grupos para falar comigo e ter intercâmbios para que quando eu voltasse, eles me corrigissem ("para que yo fueses voltando e eles me corrigiam"). Foi uma coisa fantástica. E como neste tempo tinha um programa na TV do Jô Soares que se chamava Viva o Gordo, e tinha um personagem que se chamava Gardelon, eles me identificavam como Gardelon, e eles me conhecem como Gardelon, inclusive quando eu me encontro com eles às vezes me gritam "Gardelon!” na rua. Isso foi uma coisa muito interessante. Então, o encontro foi uma querida cumplicidade de eles ajudarem naquilo que eles me estimulavam para aperfeiçoar o português mas o sotaque de Rivera continua ótimo. Eles me entendiam porque eles já tinham uma base cultura.

Entrevistador: Quais são as suas melhores memórias de seu tempo de trabalho no Colégio de Aplicação da UFRGS?

Entrevistado: Tenho muitas coisas para relatar. Foi uma experiência muito rica e um aprendizado permanente. Para mim tudo tinha mudado. Apesar de estarmos geograficamente tão pertos, somos diferentes. No começo foi bastante difícil, o processo de adaptação, escala de valores, costumes, dinâmica do ensino, postura, disciplina, cumprir horários, para mim, eram coisas sagradas; aqui, virou toda uma transformação. Alunos com tênis na sala de aula, alunos sem gravata na sala de aula. Então eu nos primeiros tempos (momentos?) lecionava como no Uruguai, com gravata e tudo. E eles não queriam que eu tirasse a roupa porque eles achavam o máximo isso. E eu vinha com gravata e tudo, como eu estava acostumado no Uruguai. Então, foram experiências muito interessantes, mas tu só te dás conta de tudo isso quando sai do teu país. Tu não podes olhar para trás... Eu tinha que olhar para frente, então os desafios que se apresentavam, eu tinha que enfrentá-los.

Entrevistador: Quais foram os seus principais desafios em seu tempo de trabalho no Colégio de Aplicação da UFRGS?

Entrevistado: Como já te expliquei, querido professor Victor, mudou tudo praticamente. Apesar de estarmos perto, somos diferentes. A única coisa que tinham de igual é a geografia física, porque forma parte da mesma província geológica conjuntamente com o Uruguai, Mesopotâmia argentina e a parte oriental do Paraguai. A posição, para mim, é de que só poderia olhar para frente, não poderia olhar para trás. Agora, em relação a quais foram as atividades de ensino de geografia mais marcantes, o que posso dizer é que haviam fatores que favoreciam a isso.

Entrevistador: Quais foram as atividades de ensino de Geografia realizadas/organizadas pelo senhor que mais lhe marcaram?

Entrevistado: O trabalho desenvolvido estava baseado fundamentalmente em aulas teórico-práticas baseadas em grupos interdisciplinares, com trabalhos de campo tanto a nível nacional quanto internacional, porque viajavam frequentemente ao 
Uruguai e Argentina - coisa que agora não se pode fazer, pois é mais difícil. O trabalho com os estagiários foi uma experiência ótima, eu gostava de trabalhar com eles porque sempre vinham com inovações. Mas devo salientar duas etapas totalmente diferentes entre Colégio de Aplicação quando era Colégio de Aplicação da Faculdade de Educação do campo central - isso foi até 1994 - e depois. A partir de 1995, com o CAp inserido dentro da UFRGS, a situação trocou totalmente. Faltou aquele suporte fantástico de estar junto à Faculdade de Educação, até os valores também... As novas diretivas, e aí se davam uma série de problemas, porque haviam estrelas de grande magnitude que queriam sobressair, sabe? Eram varias estrelas de grande magnitude que disputavam todas uma espécie de sol, aí complicou bastante a situação. Agora, o Colégio de Aplicação ganhou em que? O CAp ficou um pouco mais autônomo, mas cortar o nexo com a Faculdade de Educação tirou a dinâmica porque é definitivamente era importante a aproximação, tanto física como pessoal, com a Faculdade de Educação, pelos contatos que nós tínhamos e pela atualização que nós tínhamos em relação à teoria e a prática da educação com os grandes autores que estavam naquele momento. Então, nosso trabalho, em realidade, foi um trabalho interdisciplinar, era muito rico em todos os aspectos. Todos os anos, em março, se organizava a semana de Porto Alegre, onde se comemorava o aniversário de Porto Alegre com palestras, seminários, geralmente geografia e história eram as que promoviam as atividades conjuntas, com palestras, aulas práticas sempre percorrendo a cidade de Porto Alegre para que os alunos tivessem a noção da arquitetura, a cultura de Porto Alegre, conjuntamente com as outras disciplinas, inclusive o professor de filosofia era muito importante. Pessoalmente, publiquei em 1994 um livro de estudos sobre "O Espaço Rio-Grandense na Bacia do Prata". Outro trabalho importante foi com Sociologia: "Os Meninos de Rua", trabalho feito com intercâmbio de professores e alunos de colégios de Buenos Aires. Sempre se realizavam seminários de intercambio nacional e internacional. Foi uma experiência muito rica e única.

Entrevistador: Como o senhor percebe as diferenças no ensino de Geografia do seu tempo de trabalho para os dias atuais?

Entrevistado: A prática do ensino, o trabalho do professor mudou muito comparando com a década de 80 . O avanço da tecnologia ao serviço do ensino em todas as áreas é um grande aliado do professor em sua relação com seus alunos. Hoje está mais difícil trabalhar porque tem vários fatores que dificultam o trabalho conjunto do professor com os alunos e os alunos entre si. A situação econômica afeta muito o trabalho, a falta de recursos às vezes elementais que antes não existiam. $\mathrm{O}$ desmembramento da célula básica da sociedade como um todo: a família. A violência, o consumo de estimulantes, a intolerância em geral afetando a relação aluno-professor e escola-família. Toda esta situação que estamos enfrentando agravado com o descaso do estado com a Educação, que é a única saída para um país tornar-se de primeira magnitude e potência a nível mundial é através da Educação. Os países altamente desenvolvidos do mundo atual, todos fixaram suas metas de desenvolvimento na educação como única saída. Mas este é um processo geracional que leva duas ou três gerações para notar seus resultados positivos e irreversíveis. Então, nossa situação, continua sendo caótica, sem políticas públicas de investimentos orientadas para a Educação em todos os níveis. Enquanto a educação não seja prioritária no país, o país seguirá afundado num caos total sem saídas.

Entrevistador: Que recomendações o senhor daria aos jovens professores de Geografia? 
Entrevistado: As recomendações que eu daria para todos os jovens que já sejam estudantes de geografia ou de outras áreas do conhecimento, é que a única saída é através do estudo. Acreditar, lutar e superar obstáculos e nunca desistir de nossos sonhos, porque através do estudo de todas as áreas do conhecimento e lutando juntos é que vamos levantar nosso país. É esse Brasil que todos queremos para nós e para as futuras gerações.

\section{Referências}

CASTRO, Magali de et al. Percorrendo os caminhos da profissão docente: estudo a partir da trajetória de professoras formadas nas primeiras décadas do século XX. Belo Horizonte: PUC Minas, 2005. (Relatório de Pesquisa).

FONTANA, Roseli Cação. Como nos tornamos professoras. Belo Horizonte: Autêntica, 2000.

FREITAS, Maria Teresa de Assunção (org.). Memórias de professoras: história e histórias. Juiz de Fora: UFJF, 2000.

VIDIGAL, Luis. Os testemunhos orais na escola: história oral e projectos pedagógicos. Porto: Asa, 1996. 